\title{
Increasing Nurse Knowledge Using a Formal Lung Transplant Education Program
}

Amy Stoddard, MSN, ACNPC-AG, CCRN; Donna Lynch-Smith, DNP, ACNP-BC, APRN, NE-BC, CNL; Kate Carlson Wrammert, MSN, AGACNP-BC; Bobby Bellflower, DNSc, NNP-BC, FAANP

College of Nursing - The University of Tennessee Health Science Center - Memphis, TN

\section{Purpose}

To create a formal lung transplant educational program to increase nursing knowledge of clinical pathways of post-operative lung transplant patient care.

\section{Background}

> The International Society for Heart and Lung Transplant (ISHLT) registry noted that, as of 2017,65 lung transplant centers are in the United States.

$>2,478$ lung transplants were performed in the US in 2017 . $>$ Cleveland Clinic performed 15\% of the US lung transplants in 2017. $>$ The ISHLT has created a clinical pathway (guidelines) for postoperative care for the lung transplant patient.

D Emory University Healthcare is the only transplant center in Georgia.

$>$ The program was started in 1993 and has performed over 500 lung transplants since its creation.

Increasing problems indicated that nursing staff were not following ISHLT pathways as closely as needed to improve patient outcomes. - A basic power point had been shown to the nurses caring for lung transplant patients

$>$ No formal education classes had been developed or taught to the staff.

\section{Methods}

> Based on ISHLT clinical pathways, a daylong nursing education course was developed.

> Course content included diseases transplanted, immediate postop complications, immunosuppression, infections, rejection, and surgical overview.

> Pre-testing prior to the class, post-testing directly after the class, and a 3-month follow-up test were administered to the set of participants attending the education course

> The test included 10 questions administered during 3 timepoints.

> Due to the COVID-19 pandemic, the pre-test, post-test, and 3month follow-up test were administered by secure email. The education course was taught via Zoom.

\section{Results}

$>$ A formal lung transplant education program increased nursing knowledge of post-operative lung transplant care

$>$ From pre to posttest, the mean score improved from $72.9 \%$ to $87.6 \%$

$>$ Retention of knowledge decreased at the 3-month mark.

$>$ At the 3-month mark, the mean score dropped to $83.1 \%$ from the posttest mean of $87.6 \%$

Treatment of acute rejection and indications/qualifications for transplant were the questions that were missed $>50 \%$ of time on the 3-month posttest.

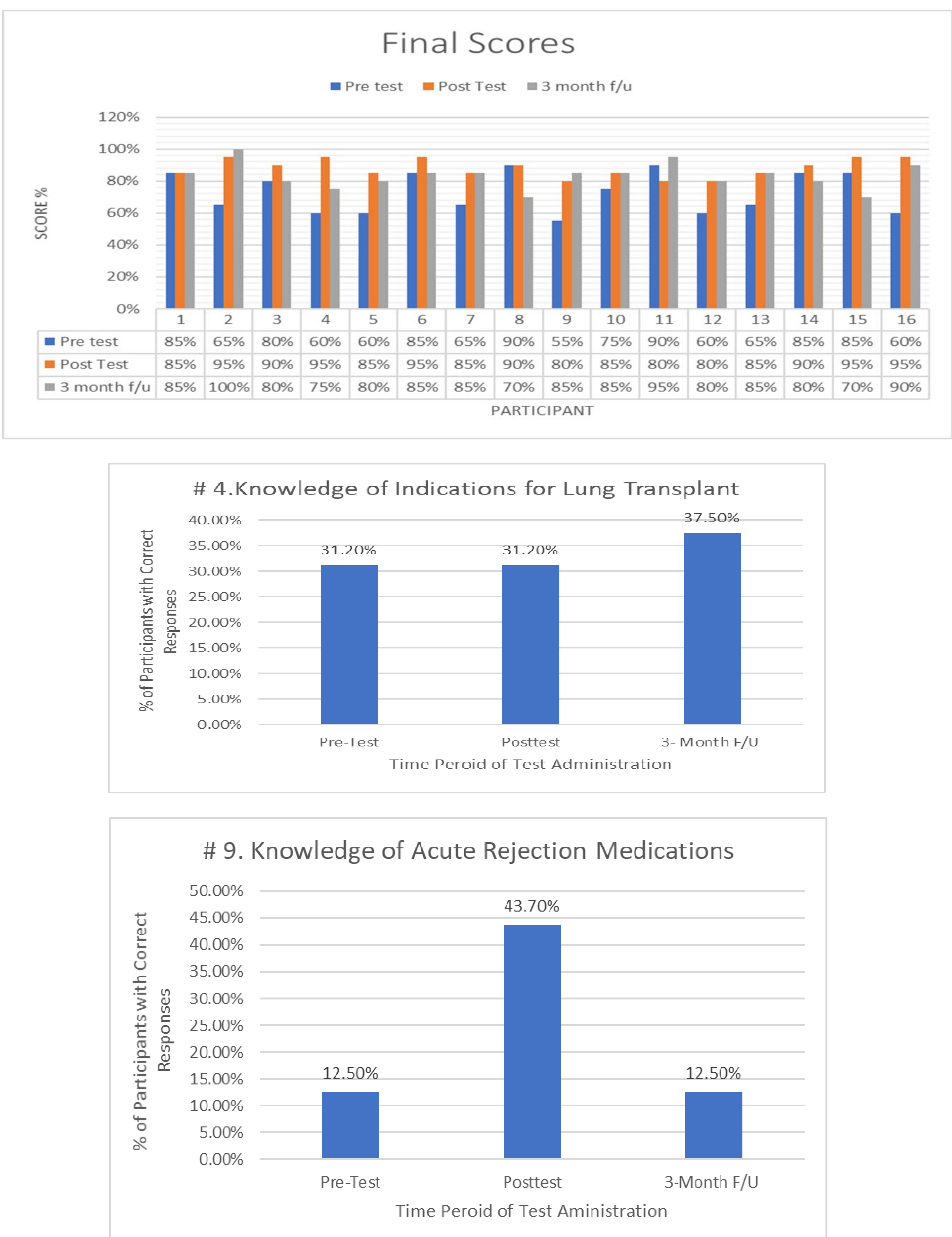

\section{Implications for Practice}

$>$ The formal education program increased nurses' knowledge of how to care for lung transplant patients.

$>$ This course will be adopted as the method for training new nurses.

The item analysis allowed us to see where the weak areas of education are most prevalent

$>$ Quarterly education will be provided to the nurses to reinforce the principles taught in the course and will focus on challenging areas such as indications for transplant and treatment of acute rejection.

$>$ Nurses who took the education course have provided feedback that it has helped them understand the "why" behind what they do.

\section{References}

Bond, L., \& Hallmark, B. (2018). Educating nurses in the intensive care unit about gastrointestinal complications: Using an algorithm embedded into doi:10.1016/j.cnc.2017.10.007

Lin, F., Gillespie, B. M., Chaboyer, W., Li, Y., Whitelock, K., Morley, N., Morrissey, S., O'Callaghan, F., \& Marshall, A. P. (2019). Preventing surgical site infections: Facilitators and barriers to nurses adherence to clinical practice guidelines: A qualitative study. JOURNAL OF CLINICAL NURSING, 28(9-10), 1643-1652. https://doi-org.ezproxy.uthsc.edu/10.1111/jocn.14766

Raines, D. (2012). Quality Improvement, Evidence-Based Practice, and Nursing Research ... Oh My! Neonatal Network, 31(4).

ost.com.ezproxy uthsc. edu/login. aspx?direct=true\&db=edo 8 AN=ejs 341034528 site=eds-live.

Sweeney, N., Calame-Mars, G., Dojlidko, D., Frank-Bader, M., Keller, R., \& Waterman, J. (2015). Preparing for a face transplant: development of a comprehensive nursing educational program. Progress in Transplantation, 25(4), 316-320. doi:10.7182/pit2015899

Valapour, M., Skeans, M. A., Smith, J. M., Israni, A. K., Snyder, J. J., Kasiske, B. L., Lehr, C. J., Uccellini, K., Lehman, R., \& Robinson, A. (2019). OPTN/SRTR 2017 annual data report. Lung. American Journal of Transplantation : Official Journal of the American Society of Transplantation and the American Society of Transplant Surgeons, 19, 404-484. https://doiorg.ezproxy.uthsc.edu/10.1111/ajt.15279

van Heerden, C., Maree, C., Yazbek, M., Janse van Rensburg, E. S., \& Leech, it. Journal of Adult \& Continuing Education, 25(2), 252 